\title{
PRODUÇÃO DE ÁLCOOIS GRAXOS SUPERIORES A PARTIR DA HIDROGENAÇÃO DE ÉSTERES METÍLICOS UTILIZANDO CATALISADORES A BASE DE COBRE
}

\author{
I. B. T. de MACEDO ${ }^{1}$, J. L. C. W. PIMENTA ${ }^{1}$, A. F. ZANETTE ${ }^{1}$, R. MENECHINI \\ $\mathrm{NETO}^{1}$, O. A. A. dos SANTOS ${ }^{1}$, L. M. M. JORGE ${ }^{1}$ \\ ${ }^{1}$ Universidade Estadual de Maringá, Departamento de Engenharia Química \\ E-mail para contato: 1mmj@deq.uem.br
}

\begin{abstract}
RESUMO -. Os álcoois superiores são de extrema importância para a indústria farmacêutica, cosméticos e como intermediários de reações. Uma das formas de obtenção de álcoois graxos superiores é a partir da hidrogenação do estearato de metila na presença de catalisadores. No presente trabalho foram realizados ensaios de hidrogenação do estearato de metila em um reator tipo autoclave (PARR) nas condições de temperatura $200^{\circ} \mathrm{C}$ e pressão 500 e 750 psi. Utilizaram-se dois catalisadores a base de cobre: um sintetizado pelo método sol-gel e o outro comercial (HiFuel R120 - Alfa Aesar). As análises de cromatografia gasosa com detecção por espectro de massa mostraram a formação de álcool superior, indicando que os catalisadores empregados apresentam atividade catalítica e são promissores para o referido processo de hidrogenação.
\end{abstract}

Palavras chave: Hidrogenação catalítica, álcool graxo, éster graxo

\section{INTRODUÇÃO}

Os álcoois graxos superiores, substâncias sólidas e de aspecto ceroso, possuem grande importância comercial, principalmente na indústria de cosméticos. A sua grande utilização se deve ao fato de serem agentes de consistência e tensoativos, portanto são utilizados amplamente na formulação de muitos produtos destinados aos cuidados da pele. Dentre os álcoois graxos de interesse industrial, destaca-se o álcool heptadecanol e o álcool estearílico. O primeiro é levemente solúvel em água, usado como um produto químico intermediário e muito utilizado em cosméticos e sabonetes, além da fabricação de surfactantes e ser fixador de perfume. Já o álcool estearílico, que é um agente de consistência e sobreengordurante, é utilizado em cremes, loções, máscaras capilares entre outros. É compatível com todo o tipo de emulsionante, bem como com emolientes, além de apresentar baixo grau de irritabilidade à pele. (BARCZA, 2014).

Mundialmente a maior parte da produção de álcoois graxos se dá por matériasprimas petroquímicas, mas as flutuações em disponibilidade e preço do óleo cru tem diminuído o desenvolvimento deste tipo de processos, favorecendo assim o uso de produtos naturais. A produção comercial de álcoois graxos baseia-se normalmente em três processos: Síntese Ziegler; Síntese Oxo; Hidrogenação de ácidos graxos ou seus ésteres a altas pressões. Os dois primeiros métodos utilizam produtos petroquímicos como matéria-prima, já na 
hidrogenação a elevadas pressões são utilizadas como matéria-prima gorduras e óleos provenientes de outras fontes, como óleos vegetais. (SANTOS, 1999)

A hidrogenação catalítica é um dos processos químicos mais importantes para a sociedade moderna e merece destaque na produção de gorduras hidrogenadas, na indústria petroquímica e farmacêutica. As reações de hidrogenação são geralmente exotérmicas e são influenciadas por fatores como catalisador, solvente, pureza do substrato e outras condições de reação, consistindo usualmente na adição de hidrogênio nas insaturações das cadeias orgânicas (BARCZA, 2014). O processo de hidrogenação se conduzido de forma completa, produzirá moléculas saturadas que apresentam interações moleculares mais fortes. Segundo estudos de Chakraborty et al (2014), a hidrogenação de ésteres metílicos de ácidos graxos, catalisada por compostos a base de ferro, tem como produtos o metanol e o álcool graxo correspondente.

Estudos anteriores como o de He et al. (2013) apontam para a possibilidade de utilização dos catalisadores a base de cobre no processo de hidrogenação de ésteres. A utilização de metais não nobres em processos catalíticos implica em uma possível mudança na metodologia convencional, que utiliza catalisadores a base de metais nobres mais caros e de difícil obtenção, agregando vantagens competitivas.

Diante disso, o presente trabalho visa o uso de catalisadores inovadores a base de cobre para serem utilizados na hidrogenação catalítica de ésteres de ácidos graxos, a fim de obter álcoois graxos de maneira mais econômica e utilizando matérias primas alternativas. Para tal, foi utilizado neste trabalho como reagente o estearato de metila e dois catalisadores distintos a base de cobres, sendo um deles comercial (HiFuel R120) e o outro um catalisador preparado previamente pela rota sol-gel.

\section{METODOLOGIA}

O equipamento utilizado é constituído basicamente de duas partes, um sistema de alimentação de gás reagente (BRGDS fabricado pela Autoclave Engineer) e por um reator do tipo autoclave (PARR). O sistema permite fornecer gás reagente e gás inerte para o reator, possui válvulas para extração de amostras e regulagem da pressão interna do reator. A reação é realizada com agitação mecânica, sendo feita em um reator de aço inoxidável.

Os catalisadores foram ativados num reator de leito fixo, a uma temperatura de $300{ }^{\circ} \mathrm{C}$ sob fluxo de uma mistura gasosa contendo $5 \%$ de hidrogênio e $95 \%$ de nitrogênio, durante 3 horas. $\mathrm{O}$ reator então foi resfriado e o catalisador foi imediatamente vertido em um recipiente contendo heptano, de modo a minimizar o contato deste com o ar.

Na preparação do catalisador para os ensaios, secou-se o catalisador úmido com heptano sob um fluxo de nitrogênio gasoso até que o catalisador se apresentasse como um pó seco. Manteve-se então o catalisador ativo e seco em um recipiente cujo ar havia sido purgado com nitrogênio a fim de evitar-se a oxidação do primeiro. Após pesado, manteve-se o catalisador submerso em heptano até o momento de sua adição no reator. 
O solvente de escolha foi o heptano, já que o éster utilizado apresenta boa solubilidade neste solvente. A solução de estearato de metila, heptano e catalisador são colocados inicialmente dentro do vaso reacional. A seguir, purgou-se o reator com nitrogênio para a retirada de quaisquer gases não-inertes presentes. Após esta etapa, iniciava-se o aquecimento do reator, sob agitação, até que este alcançasse a temperatura de $200^{\circ} \mathrm{C}$. Atingida esta temperatura, regulava-se a pressão interna do reator com válvulas de controle de pressão específicas que injetam hidrogênio no meio reacional e o mantém a uma pressão constante (500 Psi ou 750 Psi) durante todo o tempo de reação (3 horas). Para cada ensaio reacional foram definidas condições experimentais, que estão apresentadas nas tabelas 1, 2 e 3, tendo como finalidade o estudo da influência de cada condição nas amostras obtidas.

As amostras foram armazenadas em baixas temperaturas até o momento da análise para a identificação dos produtos formados na reação. A análise foi realizada por cromatografia gasosa utilizando o equipamento Agilent Technologies 7890A, com a coluna DB5, o detector utilizado foi o espectro de massa da Agilent Technologies 5975C VL MSD. A partir das analises, as porcentagens de cada gráfico foram normalizadas para o estearato de metila e o álcool de interesse.

Tabela 1 - Condições experimentais para amostras sem catalisador

\begin{tabular}{ccccccc}
\hline Amostra & $\begin{array}{c}\text { Solvente } \\
(\mathrm{mL})\end{array}$ & $\begin{array}{c}\text { Catalisador } \\
(\%)\end{array}$ & $\begin{array}{c}\text { Pressão } \\
(\mathrm{psi})\end{array}$ & $\begin{array}{c}\text { Tempo } \\
(\mathrm{h})\end{array}$ & $\begin{array}{c}\text { Temperatura } \\
\left({ }^{\circ} \mathrm{C}\right)\end{array}$ & $\begin{array}{c}\text { Estearato } \\
\text { de metila } \\
(\mathrm{g})\end{array}$ \\
\hline 1 & 100 & 0 & 500 & 3 & 200 & 6,0272 \\
2 & 100 & 0 & 750 & 3 & 200 & 6,0055 \\
\hline
\end{tabular}

Tabela 2 - Condições experimentais para amostras com "catalisador sol-gel"

\begin{tabular}{ccccccc}
\hline Amostra & $\begin{array}{c}\text { Solvente } \\
(\mathrm{mL})\end{array}$ & $\begin{array}{c}\text { Catalisador } \\
(\%)\end{array}$ & $\begin{array}{c}\text { Pressão } \\
(\mathrm{psi})\end{array}$ & $\begin{array}{c}\text { Tempo } \\
(\mathrm{h})\end{array}$ & $\begin{array}{c}\text { Temperatura } \\
\left({ }^{\circ} \mathrm{C}\right)\end{array}$ & $\begin{array}{c}\text { Estearato } \\
\text { de metila } \\
(\mathrm{g})\end{array}$ \\
\hline 3 & 100 & 5 & 750 & 3 & 200 & 6,0265 \\
4 & 100 & 10 & 750 & 3 & 200 & 6,0457 \\
5 & 100 & 5 & 500 & 3 & 200 & 6,0055 \\
6 & 100 & 10 & 500 & 3 & 200 & 6,0755 \\
\hline
\end{tabular}

Tabela 3 - Condições experimentais para amostras com catalisador Comercial

\begin{tabular}{ccccccc}
\hline Amostra & $\begin{array}{c}\text { Solvente } \\
(\mathrm{mL})\end{array}$ & $\begin{array}{c}\text { Catalisador } \\
(\%)\end{array}$ & $\begin{array}{c}\text { Pressão } \\
(\mathrm{psi})\end{array}$ & $\begin{array}{c}\text { Tempo } \\
(\mathrm{h})\end{array}$ & $\begin{array}{c}\text { Temperatura } \\
\left({ }^{\circ} \mathrm{C}\right)\end{array}$ & $\begin{array}{c}\text { Estearato } \\
\text { de metila } \\
(\mathrm{g})\end{array}$ \\
\hline 7 & 100 & 5 & 750 & 3 & 200 & 6,0234 \\
8 & 100 & 10 & 750 & 3 & 200 & 6,0091 \\
9 & 150 & 5 & 500 & 3 & 200 & 9,0150 \\
10 & 100 & 10 & 500 & 3 & 200 & 6,0039 \\
\hline
\end{tabular}




\section{RESULTADOS E DISCUSSÕES}

Em nenhum dos ensaios foi notada qualquer mudança de coloração, viscosidade, ou volume da solução após a reação. As amostras 1 e 2 , que não continham nenhum tipo de catalisador, não apresentaram a formação de nenhum álcool, o que indica a necessidade da adição do catalisador para que a reação de hidrogenação ocorra nas condições estudadas.

É possível observar que quando comparadas as amostras 3 e 5 verifica-se que o aumento da pressão aumenta significativamente a quantidade do álcool. A mesma comparação pode ser feita mantendo a pressão constante, como nas amostras 3 e 4 , dobrando a quantidade de catalisador, a quantidade de álcool formado é superior a $150 \%$. Nas amostras 3, 4 e 6 observou-se uma maior formação de álcool, sendo a 4 com a maior quantidade formada, condizente com o esperado. As condições de reação utilizadas nesse ensaio mostraram-se as mais favoráveis para a reação de hidrogenação: pressão do meio reacional de 750 psi e $10 \%$ de catalisador em relação a massa de éster. Também pode-se constatar pelas amostras 4 e 6 que mantendo-se a mesma quantidade de catalisador e aumentando-se a pressão em 50\% do valor inicial, a fração de álcool aumenta cerca de $46 \%$. A tabela 4 abaixo apresenta os valores encontrados nas análises para concentração das substancias de cada amostra contendo catalisador do tipo sol-gel.

Tabela 4 - Frações quantitativas encontradas nas amostras (catalisador sol-gel)

\begin{tabular}{ccc}
\hline Amostra & Álcool & Estearato de metila \\
\hline 3 & 0,0580 & 0,9420 \\
4 & 0,1089 & 0,8911 \\
5 & 0,0140 & 0,9860 \\
6 & 0,0428 & 0,9572 \\
\hline
\end{tabular}

A amostra 8, Tabela 5, apresentou a maior quantidade de álcool, pois as condições de reação eram idênticas a amostra 4. Avaliando-se a amostra 7 e 8 notou-se que ao manter a pressão constante e dobrar a quantidade de catalisador, os resultados equivalem a $150 \%$, sendo idêntico ao que ocorreu com catalisador do tipo sol-gel. Ao se variar a quantidade de catalisador a 500 psi, como nas amostras 9 e 10 percebe-se uma grande diferença na quantidade de álcool formado. Ressaltando que tanto a pressão quanto a quantidade de catalisador empregado nos ensaios influenciam significativamente na taxa de reação, conforme resultados presentes na tabela 5 .

Tabela 5 - Frações quantitativas encontradas nas amostras (catalisador comercial)

\begin{tabular}{ccc}
\hline Amostra & Álcool & Estearato de metila \\
\hline 7 & 0,1210 & 0,8790 \\
8 & 0,1832 & 0,8168 \\
9 & 0,0298 & 0,9710 \\
10 & 0,1605 & 0,8395 \\
\hline
\end{tabular}


A análise cromatográfica revela que vários outros compostos encontram-se presentes nas amostras de 3 a 10 . Porém não há indícios teóricos que estes produtos teriam sidos formados durante os ensaios reacionais, visto que foram detectados tanto em amostras dos ensaios e nos procedimentos de limpeza do equipamento utilizando apenas solvente puro. $\mathrm{O}$ cromatograma da amostra 10 mostra claramente os picos de maior interesse, como apresentados na figura 1 abaixo. No pico cujo tempo de retenção é de 11.841 minutos encontra-se o álcool n-heptadecanol, enquanto em 12.154 minutos encontra-se o estearato de metila. Estes compostos foram identificados pelo espectro de massa. Estudos adicionais e análises complementares serão realizados para determinar com precisão o produto, considerando-se a extensa gama de possibilidades de formação de álcoois graxos, incluindo a formação do octadecanol.

Figura 1 - Cromatograma da amostra 10

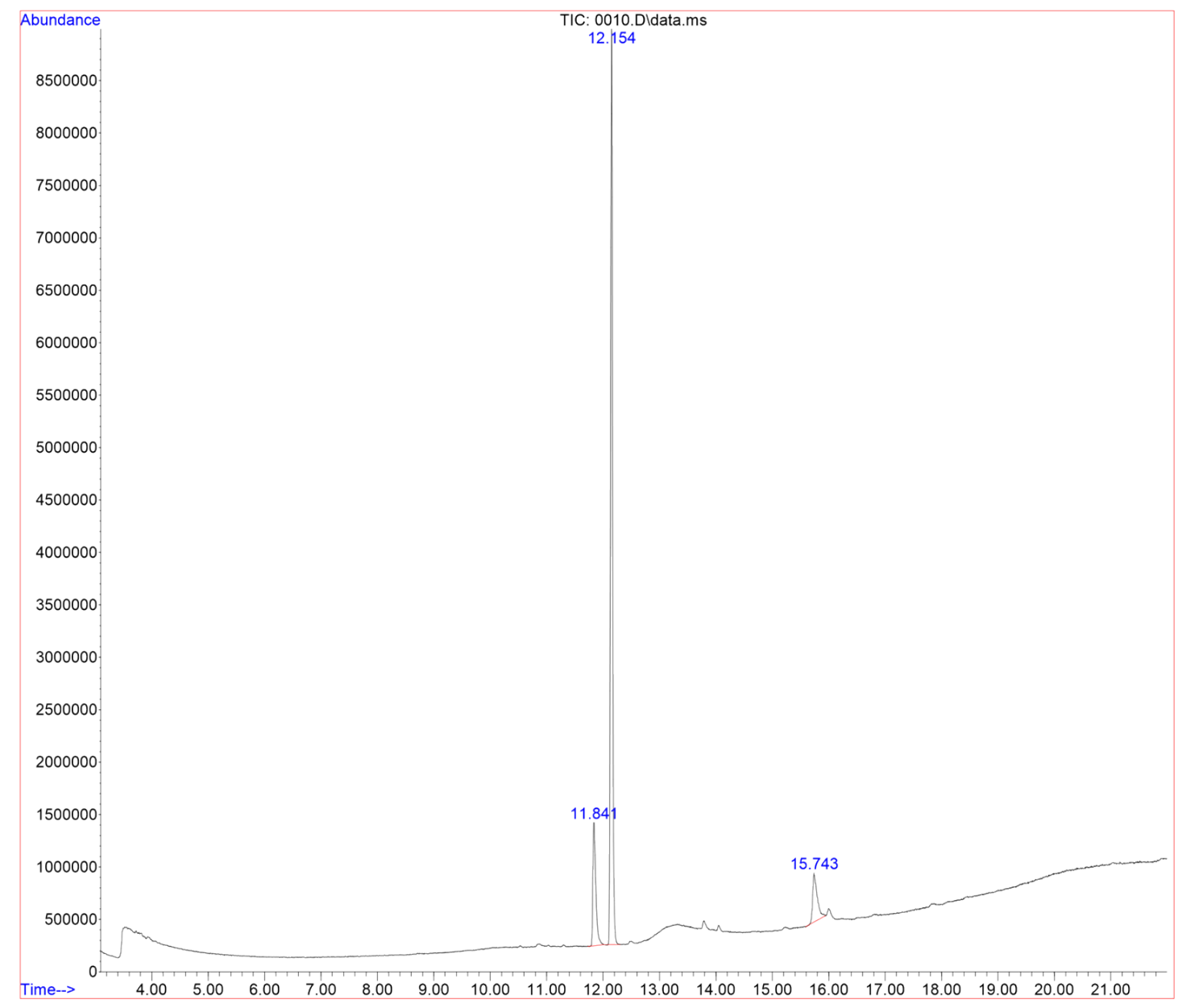




\section{CONCLUSÃO}

Os resultados mostraram que é possível a utilização dos catalisadores a base de cobre no processo de hidrogenação de ésteres metílicos a fim de produzir álcoois graxos. $\mathrm{O}$ método se mostra como uma alternativa economicamente viável, pois os ésteres metílicos podem ser obtidos de matérias primas vegetais, tornando desnecessário o uso de derivados de petróleo para obtenção de álcoois graxos superiores.

\section{REFERÊNCIAS}

BARCZA, M. V., Hidrogenação: Óleos e Gorduras. Material de apoio de ensino. Universidade de São Paulo. Acesso em 05/02/2015. Http://sistemas.eel.usp.br/docentes/arquivos/1285870/58/HidrogOleoseGorduras.pdf

GONÇALVES, G.; COLPINI, L. M. S.; MENECHINI NETO, R.; LENZI, M. K.; SANTOS, O. A. A.; JORGE, L. M. M.; Coke Formation Quantitative Analysis On Impregnated And Sol-Gel Catalysts Applied The Dry Reform Of Methane. International Journal of Materials Engineering and Technology, v. 10, n. 1, p. 45-65, 2013.

GONÇALVES, G.; LENZI, M. K.; SANTOS, O. A. A.; JORGE, L. M. M. Preparation and characterization of nickel based catalysts on silica, alumina and titania obtained by solgel method. Journal of Non-Crystalline Solids, v. 352, n. 32-35, p. 3697-3704, 2006.

HE, L., CHENG, H., LIANG, G., YU, Y., ZHAO, F. Effect of structure of $\mathrm{CuO} / \mathrm{ZnO} / \mathrm{A} 12 \mathrm{O} 3$ composites on catalytic performance for hydrogenation of fatty acid ester. Applied Catalysis A: General, v. 452, p. 88-93, 2013

SANTOS, O. A. A. Hidrogenação Seletiva do Ácido Oléico em Catalisadores de Rutênio. Tese de Doutorado. UNICAMP, 1999.

CHAKRABORTY, S.; DAI, H., BHATTACHARYA, P.; FAIRWEATHER, N. T.; GIBSON, M. S.; KRAUSE, J. A.; GUAN, H. Iron-Based Catalysts for the Hydrogenation of Esters to Alcohols, Journal of the American Chemical Society, 136 (22), p. 7869-7872, 2014. 